\title{
Butchery by Light
}

\author{
Eric Lesdema \\ Artist \\ UK \\ practicevonstroheim1@gmail.com
}

\author{
Stephanie Bolt \\ Artist \\ UK \\ iris@eyedropper.demon.co.uk
}

\section{INTRODUCTION}

In 1790, during the French Revolution, the front page of the radical newspaper 'Le Pere Duchesne' edited by Jacques Hebert featured the former, pipe in hand, pronouncing ' $\mathrm{l}$ am the true fucking Pere Duchesne' 'remember your mortality'. In 1982, scripts were being developed so as to format the Photoshop revolution for its civilisation of users.

\section{BUTCHERY BY LIGHT - PROGRAMMED OBSOLESENCE}

In 1996, a simple request was posted by Lesdema on the Rhizome email list requesting images be submitted in response to the question 'How do I know this is me?' A provocation intended to coax respondents from a programmed stupor: an obsolescence of self. Mark Tribe was the first to contribute with a three quarter length scanned photographic portrait taken in 1996 captioned 'I know it is me because I remember being there when the picture was taken in the first week of June, 1996.'

In 1996, Photoshop was hailed a new democratic system of management.

Long live the shop. Equality, fraternity and liberty have provided over 25 years of revolution. Civilisation, like Photoshop, becoming crippled to limp along out of an invisible transcendental and philosophical obstacle - a curiosity about itself, consequently warranting the physical programmed obsolescence of divergent societies into a unipolar economic and cultural space.

Lesdema's series Butchery by Light hints at civilisation's certificate of conformity embedded in a program that - with its JPEG compression - can only but allude. Butchery by Light proposes an aesthetic approach of the notion of the scandalous, a spectrum of sufferance (toleration). Stuart Hall described the series to be 'visually stunning.' Hall added with Butchery by Light 'We are near, and sometimes beyond, the limits of 'identity' ... We have been able to watch the way the photographic image first constitutes the 'space of desire' in which a diasporic attitude to identity is explored and subverted, then from the inside explodes its tenuous borders, and in synergetic complicity with other media, begins to enter another 'life', the full implications of which are impossible to predict.'

For 2015, reflecting on Hall's comments, a revised edit is being developed. A projection is proposed for EVA.

\section{REFERENCES}

Hall, S. (2001) Different. Phaidon, London. 


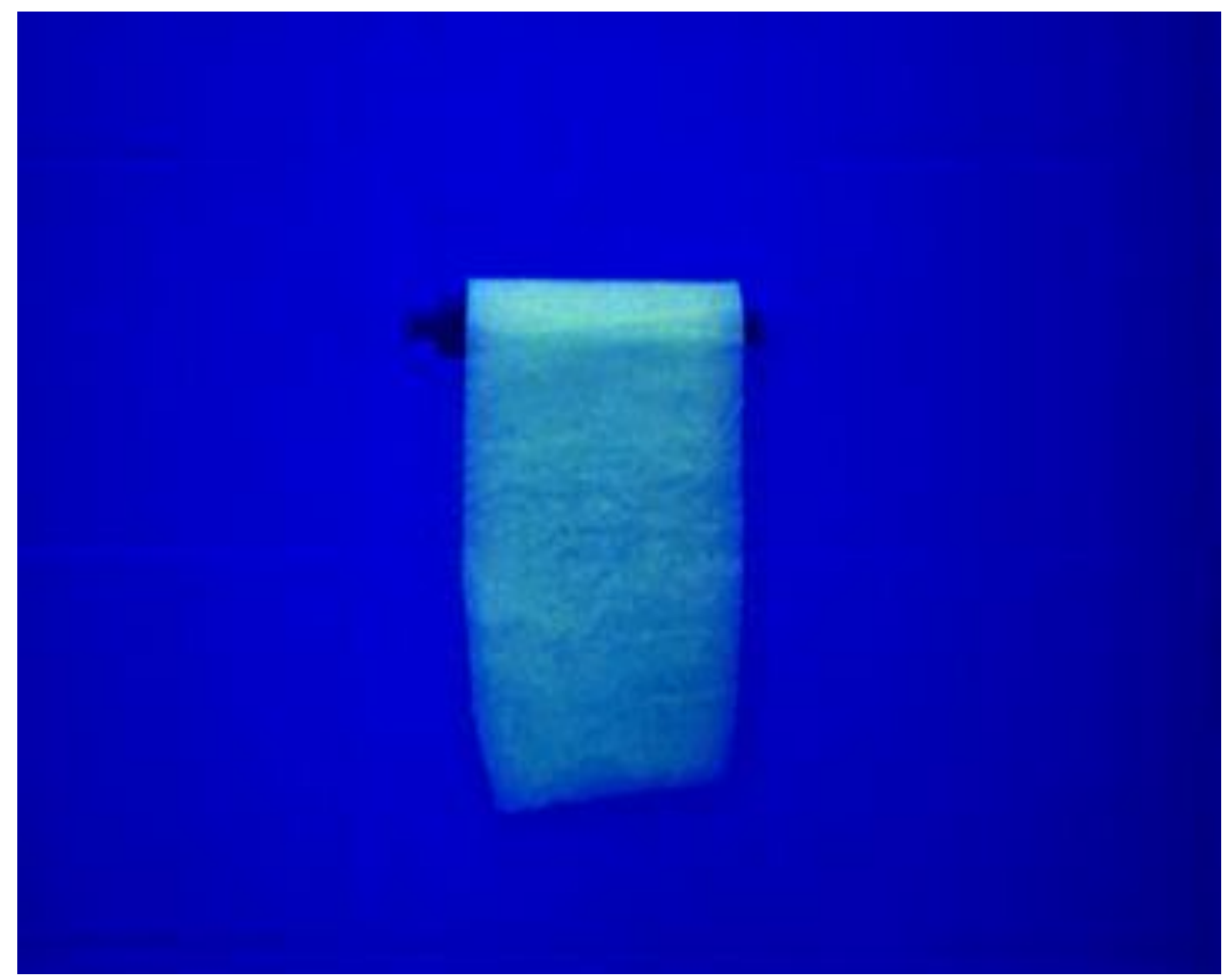

Figure 1: Butchery By Light 1, $4 \mathrm{ft} \times 3 \mathrm{ft}$ digichrome laser print from C41 colour $5 \times 4$ inch colour negative scanned, Photoshop CS4 